\title{
Diabetic ketoacidosis in people on maintenance haemodialysis: case reports and review of literature
}

\author{
APEXA KUVERJI, ${ }^{1}$ KATH HIGGINS, ${ }^{2}$ JAMES O BURTON, ${ }^{3}$ ANDREW H FRANKEL, ${ }^{4}$ CHEE KAY CHEUNG ${ }^{5}$
}

\begin{abstract}
The management of diabetes ketoacidosis (DKA) in people with normal renal function is well established. Although DKA is less common in people with end-stage kidney disease (ESKD), when it occurs, the management needs to be adapted to account for the different physiological state that these patients present with. This report presents two cases of DKA in people on maintenance haemodialysis for ESKD. Each case identifies learning points, when combined with a comprehensive literature review, generates key recommendations on the management of DKA in people on maintenance haemodialysis.
\end{abstract}

Br J Diabetes 2020;20:89-95

Key words: diabetic ketoacidosis, haemodialysis, end-stage kidney disease

\section{Introduction}

Diabetic ketoacidosis (DKA) is less common in people with endstage kidney disease (ESKD) than in those with normal renal function. Deteriorating renal function offsets poor glycaemic control by a reduction in gluconeogenesis, changes in insulin catabolism and a reduction in insulin clearance. ${ }^{1}$ Osmotic diuresis rarely occurs in patients with oligo-anuric ESKD, consequently protecting them from dehydration. Regular haemodialysis also reduces risks of severe metabolic acidosis. When DKA does occur in people on

Specialist Registrar in Nephrology and General Internal Medicine, John Walls Renal Unit, Leicester General Hospital, Leicester, UK

2 Lead Clinician for Inpatient Diabetes Care and Consultant in Diabetes Care, Honorary Senior Lecturer University of Leicester, Leicester Diabetes Centre, Leicester General Hospital, Leicester, UK

3 Professor of Renal Medicine, Honorary Consultant Nephrologist, John Walls Renal Unit, Leicester General Hospital, Leicester, UK

${ }_{4}^{4}$ Consultant Physician and Nephrologist, Imperial College Healthcare NHS Trust, London; Lead for Diabetes Care in Haemodialysis Working Group, UK

5 NIHR Academic Clinical Lecturer and Consultant Nephrologist, University of Leicester, John Walls Renal Unit, Leicester General Hospital, Leicester, UK

Address for correspondence: Dr Apexa Kuverji Specialist Registrar in Nephrology and General Internal Medicine, John Walls Renal Unit, Leicester General Hospital, Leicester, UK E-mail: apexa.kuverji@uhl-tr.nhs.uk

https://doi.org/10.15277/bjd.2020.253 maintenance haemodialysis, the treatment can be challenging and many of the protocolised management guidelines defined for patients with normal kidney function do not apply. We present two case reports of DKA occurring in people on maintenance haemodialysis and a review of the literature with recommendations for management.

\section{Case 1}

A 42-year-old male with a background of ESKD on haemodialysis for 3 years presented with vomiting for 12 hours. He was diagnosed with type 2 diabetes mellitus 10 years previously, and had started on insulin therapy within 4 months of diagnosis. His glucose control had always been poor with $\mathrm{HbA}_{1 c}$ rarely below $64 \mathrm{mmol} / \mathrm{mol}$ and reaching $190 \mathrm{mmol} / \mathrm{mol}$. He had previously had three admissions for DKA since starting haemodialysis. He had undergone haemodialysis the day before admission, after which he felt clammy, nauseated and lethargic. The following morning his carer had noticed that he looked unwell and called the paramedics, who tested his capillary blood glucose (CBG) and found this to be $26 \mathrm{mmol} / \mathrm{L}$. His heart rate was 108 beats/min and blood pressure was 130/51 $\mathrm{mmHg}$.

On arrival at the emergency department (ED) his Glasgow Coma Score (GCS) was 15/15 and he was clinically euvolaemic. His blood tests are shown in Table 1. He was diagnosed with DKA and treatment was initiated.

He was started on an intravenous infusion of $0.9 \%$ sodium chloride with $40 \mathrm{mmol} / \mathrm{L}$ potassium chloride within $30 \mathrm{~min}$ of presentation to ED. This infusion ran for $1 \mathrm{~h}$ but was changed to $0.9 \%$

Table 1 Laboratory data for case 1

\begin{tabular}{|c|c|c|c|c|}
\hline $\begin{array}{l}\text { Blood results (normal } \\
\text { values and units) }\end{array}$ & $\begin{array}{l}\text { On } \\
\text { admission }\end{array}$ & $1 \mathrm{~h}$ & $3 \mathrm{~h}$ & $14 \mathrm{~h}$ \\
\hline $\mathrm{pH}(7.35-7.45)$ & 7.296 & 7.314 & 7.345 & 7.375 \\
\hline Bicarbonate (22-29 mmol/L) & 19.2 & 20.9 & 24.6 & 26.5 \\
\hline Potassium (3.5-5.3 mmol/L) & 4.9 & 5.0 & 5.0 & 5.1 \\
\hline Ketones (<0.6 mmol/L) & 5.8 & & 0.2 & 0.1 \\
\hline CBG (mmol/L) & 26 & 20.8 & 12.7 & 8.1 \\
\hline Urea (2.5-7.8 mmol/L) & 24.7 & & & 24.1 \\
\hline Creatinine $(60-120 \mu \mathrm{mol} / \mathrm{L})$ & 666 & & & 702 \\
\hline
\end{tabular}


sodium chloride only, after the repeat potassium result came back at $5.0 \mathrm{mmol} / \mathrm{L}$. This infusion ran slowly at $100 \mathrm{~mL} / \mathrm{h}$.

His weight was $77 \mathrm{~kg}$. He was started on a fixed rate intravenous insulin infusion (FRIII) at 0.1 unit $/ \mathrm{kg} / \mathrm{h}$ and then changed to a variable rate intravenous insulin infusion (VRIII) after $3 \mathrm{~h}$ as his DKA had resolved. The initial pH of 7.29 suggests that the DKA was borderline. The resolution of DKA within $3 \mathrm{~h}$ supports this diagnosis. The VRII infusion continued until transfer to the renal ward $11 \mathrm{~h}$ later. He was prescribed his regular Novomix $30^{\circledR}$ subcutaneous insulin for the following morning and VRIII was stopped the next day, with regular point-of-care testing of his CBG and ketones. He was dialysed the following afternoon as per his usual schedule. He was reviewed 3 days later by the diabetes team for his subcutaneous insulin dosing.

\section{Case 2}

A 34-year-old female with a background of type 1 diabetes mellitus, left ventricular systolic dysfunction and ESKD secondary to diabetic nephropathy presented directly to the renal department with vomiting. She had missed a session of haemodialysis and had last dialysed 4 days previously. She had felt well on the previous day, but was drowsy on presentation and had been vomiting for the past 12 hours. More recently the vomitus was coffee-ground in nature.

Her blood pressure was 140/83 mmHg, heart rate was 98 beats/min and oxygen saturations were $98 \%$ on room air. Her GCS was 10/15 (E1, M6, V3) and no focal neurological deficit was identified. She was clinically euvolaemic, with moist mucus membranes, no evidence of pulmonary oedema and had longstanding anuria. Her Permcath (tunnelled dialysis catheter) was clean at the exit site. Her target weight was $59.7 \mathrm{~kg}$, but there was no weight available on admission due to her clinical condition. Her blood tests are shown in Table 2. She was transferred from the ward to the renal High Dependency Unit for cardiac monitoring and, in view of her level of acidosis and low GCS, the Intensive Care Unit (ICU) team was informed. ECG showed widespread tented $T$ waves and no other abnormalities. Due to the anticipated time taken to start dialysis, an intravenous. insulin-dextrose infusion was given as per local protocol for hyperkalaemia. She was started on a FRIII of 8 units/h, and the plan was to dialyse for $4 \mathrm{~h}$ with a low pump speed to ameliorate the risk of haemodynamic instability or rapid reductions in plasma osmolality. In view of the coffee-ground vomiting, low molecular weight heparin was withheld and intravenous omeprazole was prescribed.

When attempting to start haemodialysis, the patient's Permcath (which had been exchanged 10 days previously) did not aspirate well and could not be used. An alteplase lock was unsuccessful, so a urokinase infusion (25,000 units per lumen) was given over $3 \mathrm{~h}$, which successfully unblocked the catheter. The patient had central venous stenosis and occlusions from previous venous access, resulting in difficulty in gaining alternative vascular access. A second peripheral venous cannula could not be placed despite multiple attempts.

At $4 \mathrm{~h}$, when repeat blood tests showed improving acidosis and hyperglycaemia but an increase in ketones, the FRIII was increased to 9 units/h. Approximately $12 \mathrm{~h}$ after the initial presentation, the patient was started on haemodialysis. CBG levels were closely monitored during haemodialysis for hypoglycaemia. Hypoglycaemia would have to be treated by stopping haemodialysis and giving intravenous dextrose via the Permcath.

Once $4 \mathrm{~h}$ of haemodialysis was completed, the patient was started on $125 \mathrm{~mL} / \mathrm{h} 10 \%$ dextrose as her CBG was $6.0 \mathrm{mmol} / \mathrm{L}$. By the following morning her DKA had resolved (ketones 0.6 $\mathrm{mmol} / \mathrm{L}, \mathrm{CBG} 8.3 \mathrm{mmol} / \mathrm{L}$ ) and her GCS recovered. The FRIII was reduced from 8 units/h to 6 units/h until midday, when her CBG dropped to 3.3, at which point the FRIII was stopped, VRIII was commenced and intravenous $10 \%$ dextrose continued.

She was kept on a reduced dose VRIII and intravenous dextrose $10 \%$ for $48 \mathrm{~h}$ due to anorexia and episodes of hypoglycaemia, with alternate-day haemodialysis to remove excess fluid. She continued to receive her long-acting insulin (Levemir ${ }^{\circledR}$ ) at the same dose she was on prior to admission. She remained in hospital for a total of 10 days and was also treated with intravenous vancomycin for line sepsis. Blood cultures taken from the line 6 days prior to admission had grown Staphylococcus aureus, and C-reactive protein on admission was $94 \mathrm{mg} / \mathrm{L}$.

Table 2 Laboratory data for case 2

\begin{tabular}{|c|c|c|c|c|c|c|c|}
\hline Blood results (normal values and units) & On admission & $1 \mathrm{~h}$ & $2 \mathrm{~h}$ & $3 \mathrm{~h}$ & $4 \mathrm{~h}$ & $10 \mathrm{~h}$ & $18 \mathrm{~h}$ \\
\hline $\mathrm{pH}(7.35-7.45)$ & 7.022 & & 7.099 & 7.168 & & 7.284 & 7.410 \\
\hline Bicarbonate (22-29 mmol/L) & 7.2 & & 9.1 & 11.1 & & 18.8 & 26.1 \\
\hline Potassium (3.5-5.3 mmol/L) & 7.3 & & 4.7 & 4.5 & & 5.2 & 3.1 \\
\hline Ketones (<0.6 mmol/L) & 7.5 & 6.7 & 6.4 & 5.9 & 6.8 & 2.6 & 2.2 \\
\hline CBG (mmol/L) & $>47$ & $\mathrm{HI}$ & 44 & 35 & 32 & 12 & 6 \\
\hline Urea (2.5-7.8 mmol/L) & 27.8 & & & & & & 7.2 \\
\hline Creatinine (60-120 $\mu \mathrm{mol} / \mathrm{L})$ & 1149 & & & & & & 361 \\
\hline Lactate $(<2 \mathrm{mmol} / \mathrm{L})$ & 1.2 & & 1.8 & 2.1 & & 1.0 & 0.7 \\
\hline
\end{tabular}




\section{Discussion}

These two cases illustrate how the management of DKA in a patient with ESKD on maintenance haemodialysis is complex and multifactorial. Joint British Diabetes Society (JBDS) and American Diabetes Association (ADA) guidelines for the management of DKA in adults suggest that "special attention and caution" needs to be paid to those with kidney failure when it comes to fluid balance and potassium replacement. However, there is no further detail regarding the potential problems and nuances of managing this condition in this particular group of patients. ${ }^{2}$

\section{Review: methodology and search strategy}

We carried out a literature search of articles published in PubMed. The electronic search strategy on 22 October 2019 was as follows: disease (DKA OR Diabetic ketoacidosis OR ketoacidosis) AND association (haemodialysis OR dialysis). A total of 136 papers were identified, of which 122 were excluded by title and abstract evaluation as they were deemed irrelevant. This left 14 papers for analysis, shown in Table 3. Five case reports, five observational studies, one meta-analysis of observational studies and three literature reviews were analysed..$^{3-16}$

Although six of these articles focused on the management of dialysis-associated hyperglycaemia (with some patients presenting with ketoacidosis), some key themes have emerged that should be considered when managing DKA in this group of patients.

\section{Hyperglycaemia versus risk of adverse glucose events (how much insulin?)}

In patients with ESKD, delayed insulin clearance can increase the risk of hypoglycaemia, and therefore the titration of insulin infusion can be complicated. ' Schaapveld-Davis et al found that there was a significantly increased risk of adverse glucose events (hypoglycaemia $<4.0 \mathrm{mmol} / \mathrm{L}$ or rate of reduction of glucose $>11.1$ $\mathrm{mmol} / \mathrm{L} / \mathrm{h}$ ) in patients with ESKD who presented with DKA compared with a control group of those with an estimated glomerular filtration rate $\geq 60 \mathrm{~mL} / \mathrm{min} / 1.73 \mathrm{~m}^{2}(33 / 44$ (75\%) vs 16/44 (36\%), $\mathrm{p}<0.0001)$. A similar number of patients in both groups received a bolus of insulin before the insulin infusion was started $(93.2 \%$ in ESKD group vs $81.8 \%$ in controls, $p=0.2$ ). However, the ESKD group received a higher cumulative bolus dose of insulin, independent of potassium levels at diagnosis. ${ }^{8}$

The ADA consensus recommends a rate of reduction of glucose by $50-70 \mathrm{mg} / \mathrm{dL} / \mathrm{h}$ (equating to $2.8-3.9 \mathrm{mmol} / \mathrm{L} / \mathrm{h}$ ), and although this is aimed at all adults (and not specifically those with ESKD), it is much lower than the previous recommendations from Tzamaloukas et al for dialysis-associated hyperglycaemia of 5.9-6.9 $\mathrm{mmol} / \mathrm{L} / \mathrm{h} .{ }^{15-17}$ The JBDS guideline recommends a target reduction of CBG by $3.0 \mathrm{mmol} / \mathrm{L} / \mathrm{h}$ in all adults with DKA. ${ }^{2}$ The review by Seddik et $a l,{ }^{9}$ which focused on DKA specifically in people with ESKD, recommends a rate of reduction of glucose of $2.8-3.3 \mathrm{mmol} / \mathrm{L} / \mathrm{h}$ and suggests starting an insulin infusion at a lower dose of 0.050.07 units $/ \mathrm{kg} / \mathrm{h}$ to achieve this.

When dosing insulin, another factor to consider is that glucose homeostasis and insulin resistance change with haemodialysis. In non-diabetic adults on MHDx, uraemia-induced insulin resistance improved resulting in better glucose metabolism after haemodialysis. ${ }^{18}$ Interstitial glucose significantly decreases during haemodialysis, with the nadir at the 3-hour point, and then increases post-dialysis. ${ }^{19}$ Adjustment of insulin infusion during haemodialysis and the period after should be considered to reduce the extreme variability in glycaemic control and risk of hypoglycaemia. This is considered standard practice for those who are sensitive to insulin or at risk of hypoglycaemia.

As described in Case 2, starting insulin at $0.1 \mathrm{units} / \mathrm{kg} / \mathrm{h}$ did not adequately resolve the ketoacidosis and increasing the infusion to 0.15 units $/ \mathrm{kg} / \mathrm{h}$ improved the ketoacidosis but resulted in persistent hypoglycaemic episodes in the subsequent days. This was complicated by anorexia, limited vascular access and inability to infuse intravenous glucose to treat hypoglycaemia whilst on haemodialysis. Reflecting on this case, a lower dose of the patient's long-acting insulin or starting the FRII at a lower dose of 0.05-0.07 units $/ \mathrm{kg} / \mathrm{h}$ may have helped to reduce adverse glucose events. However, the risks of slowing resolution of ketoacidosis must be weighed against risks of hypoglycaemia when deciding on the rate of insulin infusion. Furthermore, the FRIl carried on for $4 \mathrm{~h}$ longer than was required. Although the diabetes team reviewed the patient later in the admission for her insulin management, involving the diabetes team earlier in this patient's care may have helped identify and reduce the risks of hypoglycaemia.

The messages from Case 2 highlight the increased risk of hypoglycaemia and the need for consideration of reduction of the rate of insulin infusion to mitigate this risk. It is important to consider the timing of haemodialysis as dialysis is associated with a change in insulin resistance and glucose homeostasis. Once the DKA is resolved, we recommend switching from FRIII to a reduced dose-adjusted VRIII to be given until anorexia is resolved.

\section{Risk of hypokalaemia versus hyperkalaemia}

People with ESKD are at a higher risk of hyperkalaemia. An observational study by Tzamaloukas et a/13 reported higher initial serum potassium levels in MHDx patients (6.1 $1.3 \mathrm{mmol} / \mathrm{L}) \mathrm{com}$ pared with patients on peritoneal dialysis who presented in DKA $(5.0 \pm 1.0 \mathrm{mmol} / \mathrm{L} ; \mathrm{p}=0.006)$. The frequency of hyperkalaemia was also higher in DKA than in non-ketotic hyperglycaemia. ${ }^{13,15,16}$ Current JBDS DKA guidelines suggest adding $40 \mathrm{mmol}$ potassium chloride to $0.9 \%$ sodium chloride infusion if the potassium falls between 3.5 and $5.5 \mathrm{mmol} / \mathrm{L}$ 'and the patient is passing urine'. ${ }^{2}$

An observational study of patients on renal replacement therapy who developed hyperglycaemia found that hyperkalaemia in this setting often resolves with insulin infusion alone, and haemodialysis may be reserved for cases of severe hyperkalaemia with the presence of ECG changes. ${ }^{11}$ Only two out of nine episodes of DKA required potassium replacement, and these cases were due to protracted vomiting prior to presentation.

As people on MHDx are frequently anuric, routine potassium replacement should be avoided in this population. In Case 1 the serum potassium concentration at presentation was normal and remained within normal limits throughout insulin therapy, confirming the physiological understanding that there is an increase in total body stores of potassium due to ESKD. 
Table 3 Summary of articles reviewed

\begin{tabular}{|c|c|c|c|}
\hline Author & Type of article & Cohort/subject & Key findings/ learning points \\
\hline $\begin{array}{l}\text { Catalano } \\
\text { et al, 19983 }\end{array}$ & Case report & $\begin{array}{l}\text { DKA in patient with } \\
\text { chronic kidney disease } \\
\text { stage } 5\end{array}$ & $\begin{array}{l}\text { Acute respiratory distress syndrome/pulmonary oedema } \\
\text { was attributed to possible endothelial and epithelial } \\
\text { damage or infusion of large volume of fluids in the } \\
\text { treatment of DKA.Pulmonary oedema was treated with } \\
\text { insulin infusion and haemodialysis }\end{array}$ \\
\hline $\begin{array}{l}\text { Blicker et al, } \\
2004^{4}\end{array}$ & Case reports & DKA in a MHDx patient & $\begin{array}{l}\text { Recommendations: } \\
\text { - Do not routinely give potassium supplementation } \\
\text { - Small volume fluid resuscitation with frequent } \\
\text { re-assessment } \\
\text { - Treat significant metabolic acidosis, volume overload or } \\
\text { hyperkalaemia with emergency haemodialysis } \\
\text { - Important to search for precipitating cause }\end{array}$ \\
\hline $\begin{array}{l}\text { Gupta et al, } \\
2008^{5}\end{array}$ & Case report & $\begin{array}{l}\text { DKA in MHDx patient } \\
\text { with neurological } \\
\text { complications }\end{array}$ & $\begin{array}{l}\text { - Osmotic translocation of fluid from intracellular } \\
\text { compartment to extracellular due to hyperglycaemia } \\
\text { can cause pulmonary oedema } \\
\text { - Haemodialysis may cause drastic reduction in plasma } \\
\text { tonicity causing neurological complications }\end{array}$ \\
\hline $\begin{array}{l}\text { Varma et al, } \\
2016^{6}\end{array}$ & Case report & $\begin{array}{l}\text { DKA in ESKD patient } \\
\text { pre-initiation of MHDx }\end{array}$ & $\begin{array}{l}\text { - Fixed rate insulin infusion with aliquots of concentrated } \\
\text { IV dextrose as required if risk of fluid overload } \\
\text { - Insulin is renally excreted and may require dose } \\
\text { adjustments }\end{array}$ \\
\hline
\end{tabular}

Yamada et al, Case report $2017^{7}$

SchaapveldDavis et al, $2017^{8}$

Observational retrospective study

Seddik et al, Literature review DKA in MHDx patients $2019^{9}$

Popli et al, $2013^{10}$

Observational
study

12 patients ( 4 on MHDx) who were alert with extreme hyperglycaemia vs 12 patients ( 7 on MHDx) who had impaired sensorium with extreme hyperglycaemia

\section{Tzamaloukas Observational Episodes of} et al, 1987'11 study

Tzamaloukas et al, 1988 12
Observational study hyperglycaemia in 5 MHDx patients and 10 PD patients. 9 out of 73 episodes of hyperglycaemia had ketoacidosis

Episodes of hyperglycaemia in $8 \mathrm{MHDx}$ patients and $15 \mathrm{PD}$ patients. 17 episodes (3 MHDx patients) of hyperglycaemia with ketoacidosis

\section{Limitations}

Cause of pulmonary oedema was unclear

Recommendations based on understanding of pathophysiology only Does not recommend a rate of insulin infusion

Recommended rate of reduction of tonicity $(<3 \mathrm{mOsm} / \mathrm{kg} / \mathrm{h})$ is based on values in NKH crisis

Patient presented prior to starting MHDx and had some residual renal function

No ketone measurement or result specified. Ketonaemia inferred from raised anion gap metabolic acidosis

ESKD patients received higher cumulative doses of insulin via bolus doses ( $14.5 \pm 7.0$ vs $9.7 \pm 1.9$ units), which could be attributing to the increased adverse glucose events

The parameters recommended for reduction of ketones, bicarbonate and CBG based on DKA guidelines for all patients, not specifically for those with ESKD

Small observational study with limited generalisability

Small study pooling PD and hyperglycaemia but not significantly associated with MHDx patients ketoacidosis specifically.

Treatment with insulin alone reduced hyperglycaemia and hyperkalaemia

Potassium replacement was only required in 2 DKA cases due to protracted vomiting (normal potassium at presentation)

- Frequency of hyperglycaemic ketoacidosis reduced after starting haemodialysis.

- Insulin infusion 1-3 units/h corrected ketoacidosis, hyperglycaemia and pulmonary oedema
Small study with pooled data of MHDx and PD patients 
Table 3 Summary of articles reviewed (continued)

\begin{tabular}{|c|c|c|c|c|}
\hline Author & Type of article & Cohort/subject & Key findings/ learning points & Limitations \\
\hline $\begin{array}{l}\text { Tzamaloukas, } \\
2005^{13}\end{array}$ & $\begin{array}{l}\text { Observational } \\
\text { study }\end{array}$ & $\begin{array}{l}\text { Comparison of potassium } \\
\text { and acid disorder in } 22 \\
\text { DKA episodes vs } \\
21 \text { non-ketotic acidosis in } \\
\text { dialysis patients }\end{array}$ & $\begin{array}{l}\text { - Insulin therapy alone can treat hyperkalaemia and acid } \\
\text { disorder in dialysis-associated hyperglycaemia } \\
\text { - Initial serum potassium was higher in MHDx patients } \\
(6.1 \pm 1.3 \mathrm{mmol} / \mathrm{L}) \text { than in PD patients }(5.0 \pm 1.0 \mathrm{mmol} / \mathrm{L}) \\
(\mathrm{p}=0.006)\end{array}$ & $\begin{array}{l}\text { Patients on MHDx and PD pooled } \\
\text { together and numbers of each } \\
\text { not stated }\end{array}$ \\
\hline $\begin{array}{l}\text { Tzamaloukas, } \\
2008^{14}\end{array}$ & $\begin{array}{l}\text { Meta-analysis of } \\
\text { retrospective } \\
\text { observational } \\
\text { studies }\end{array}$ & $\begin{array}{l}\text { Comparison of } 491 \\
\text { reports of dialysis- } \\
\text { associated } \\
\text { hyperglycaemia vs } 1036 \\
\text { reports of DKA and } 403 \\
\text { reports of NKH in patients } \\
\text { with preserved renal } \\
\text { function }\end{array}$ & $\begin{array}{l}\text { - Hyperglycaemia contributes to increased extracellular } \\
\text { tonicity causing fluid shifts and increased extracellular } \\
\text { fluid volume. Serum tonicity was lowest in the dialysis } \\
\text { group, attributed to the fluid shifts and lack of osmotic } \\
\text { diuresis (in contrast to DKA in preserved renal function } \\
\text { where hypovolaemia occurs from osmotic diuresis and } \\
\text { net loss of water) } \\
\text { - Consider emergency haemodialysis in pronounced } \\
\text { oedema, severe hyperglycaemia and severe pulmonary } \\
\text { oedema }\end{array}$ & $\begin{array}{l}\text { Many potential sources of error } \\
\text { including: } \\
\text { - Inaccurate reporting of serum } \\
\text { glucose and sodium measure- } \\
\text { ments during treatment with } \\
\text { insulin from studies } \\
\text { - Errors in the theoretical } \\
\text { formula used to calculate } \\
\text { tonicity changes secondary to } \\
\text { hyperglycaemia }\end{array}$ \\
\hline $\begin{array}{l}\text { Tzamaloukas } \\
\text { et al, } 2008^{15}\end{array}$ & Literature review & $\begin{array}{l}\text { Patients on MHDx and } \\
\text { severe hyperglycaemia }\end{array}$ & $\begin{array}{l}\text { - Higher levels of potassium are found in patients with } \\
\text { DKA on MHDx than PD or NKH. Consider emergency } \\
\text { haemodialysis only if ECG changes related to } \\
\text { hyperkalaemia or severe pulmonary oedema (there is a } \\
\text { risk of rapid change in tonicity with HD) }\end{array}$ & $\begin{array}{l}\text { The effects of rapid reduction in } \\
\text { hypertonicity have not been } \\
\text { studied in DKA in particular, but } \\
\text { recommendations have been } \\
\text { drawn from NKH reports }\end{array}$ \\
\hline $\begin{array}{l}\text { Tzamaloukas } \\
\text { et al, } 2011^{16}\end{array}$ & Literature review & $\begin{array}{l}\text { Potassium concentration } \\
\text { in dialysis-associated } \\
\text { hyperglycaemia }\end{array}$ & $\begin{array}{l}\text { Frequency of hyperkalaemia is higher in DKA than NKH. } \\
\text { Insulin bolus of } 0.15 \text { units } / \mathrm{kg} \text { is recommended followed by } \\
\text { infusion of } 0.1 \text { unit } / \mathrm{kg} / \mathrm{h} \text { with recommended rate of } \\
\text { glucose reduction by } 5.6-6.9 \mathrm{mmol} / \mathrm{L} / \mathrm{h}\end{array}$ & $\begin{array}{l}\text { Treatment recommendations } \\
\text { given for hyperkalaemia in } \\
\text { dialysis-associated } \\
\text { hyperglycaemia setting, not } \\
\text { specifically for DKA }\end{array}$ \\
\hline
\end{tabular}

In Case 2, where hyperkalaemia with ECG changes was present, the literature suggests emergency haemodialysis. 5,9,14 If there is potential for delay in achieving this, we suggest small boluses of intravenous insulin as per local hyperkalaemia management guidelines. In this case, 10 units of insulin Actrapid $^{\circledR}$ in $50 \mathrm{~mL} 50 \%$ glucose was administered intravenously as the immediate treatment for hyperkalaemia. This is likely to have contributed to the worsening hyperglycaemia in the first hour of treatment.

We suggest careful monitoring of potassium in people on MHDx and to consider replacement with potassium chloride only if potassium levels are below $3.5 \mathrm{mmol} / \mathrm{L}$ and acidosis has been corrected. 4,9 Serum potassium levels should be re-checked after administration of potassium chloride. In specific cases of hyperkalaemia in DKA in a person with ESKD where the person is awaiting haemodialysis, the medical management of hyperkalaemia may need to be adapted. When insulin is administered to correct the hyperkalaemia, we suggest that the addition of $50 \%$ glucose/dextrose may not be required unless the CBG is less than $14 \mathrm{mmol} / \mathrm{L}$. Dialysis is recommended if hyperkalaemia is severe and associated with ECG changes.

\section{Hypertonicity and fluid balance}

DKA and hyperosmolar hyperglycaemic state are often considered as separate entities within management guidelines; however, there is often overlap in the clinical and biochemical picture. Umpierrez et al estimate that approximately $20-30 \%$ of patients presenting with hyperosmolar hyperglycaemic state have concomitant ketoacidosis. ${ }^{20}$ The presence of hyperosmolality is common in DKA, occurring in up to $37 \%$ of laboratory findings, ${ }^{17}$ and has been considered significant in grading the severity of DKA in all adults. ${ }^{21}$

There are concerns regarding rapid reduction in tonicity in people with DKA being associated with cerebral oedema and pontine myelinosis. 5,9,10 The recommended rate of reduction of tonicity $(<3$ $\mathrm{mOsm} / \mathrm{kg} / \mathrm{h}$ ) based on non-ketotic hyperglycaemic crisis is not specific to those with renal failure. ${ }^{17}$

A meta-analysis of observational studies conducted by Tzamaloukas et al in 2008 found that serum tonicity was lower in the dialysis group than in those with preserved renal function. They suggested that, when hyperglycaemia contributes to increased extracellular tonicity, the fluid shift increases extracellular fluid volume. When DKA occurs in people with preserved renal function, this results in osmotic diuresis and net loss of water, which increases extracellular tonicity. In people on MHDx there is no osmotic diuresis, resulting in increased extracellular volume and reduced extracellular tonicity compared with those without renal failure. ${ }^{14}$ A reduction of hypertonicity in dialysis-associated hyperglycaemia is seen with insulin therapy alone and aggressive fluid resuscitation is rarely required. We recommend careful assessment of fluid volume status and small boluses $(250 \mathrm{~mL})$ of intravenous fluids if deemed hypovolaemic, with frequent re-assessment to avoid fluid overload. This assessment may be complicated if the patient has 
DKA associated with sepsis. Invasive monitoring and vasopressor support in a critical care setting may be required to optimise intravascular volume status in complex sepsis cases.

\section{Haemodialysis}

During haemodialysis, lower glucose dialysates may influence glucose control and increase the risk of hypoglycaemia due to movement of glucose down a concentration gradient. ${ }^{22}$ There are also concerns that haemodialysis may cause a rapid reduction in hypertonicity in DKA, which could potentially lead to adverse neurological outcomes. In one case report by Gupta et $a l,{ }^{5}$ haemodialysis caused a rapid reduction in tonicity $(14.5 \mathrm{mOsm} / \mathrm{kg} / \mathrm{h})$ and was stopped $1.5 \mathrm{~h}$ after initiation due to fears that this is approximately five times faster than the recommendation.

Another complication that should be considered with haemodialysis, especially in patients who have reduced GCS at presentation or have missed sessions of dialysis, is Dialysis Disequilibrium Syndrome (DDS). The pathophysiology of DDS is unclear, but it is proposed that there is a reverse osmotic shift due to rapid removal of small solutes such as urea, which causes cerebral oedema. ${ }^{23}$ Risk factors for developing DDS include a high serum urea level $>60 \mathrm{mmol} / \mathrm{L}$, first haemodialysis session, extremes of age, pre-existing neurological disease or concomitant disorders associated with cerebral oedema. ${ }^{24}$ There are no case reports of DDS occurring in the presence of DKA. However, given that DKA may present with reduced GCS, it is an important differential diagnosis to consider.

In Case 1, haemodialysis was not required at the time of presentation and was given on the patient's normal dialysis day with no complications. He also had no risk factors for developing DDS. In Case 2 there was a delay in starting haemodialysis due to problems with vascular access, and she was at risk of DDS (having presented with low GCS). In order to reduce this risk, we initiated slower pump speed haemodialysis at $180 \mathrm{~mL} / \mathrm{min}$ blood flow and frequently monitored her GCS throughout the session.

We suggest careful monitoring of CBG during and after haemodialysis due to the increased risk of hypoglycaemia. Studies suggest that emergency haemodialysis should be considered in the event of severe hyperkalaemia with ECG changes or severe refractory pulmonary oedema. ${ }^{5,9,14}$ In cases where hyperkalaemia is not a complicating factor, isolated ultrafiltration may be used for fluid removal in the event of pulmonary oedema if there is a risk of rapid reduction in tonicity or DDS.

\section{Identify underlying cause}

It is important to identify any precipitating causes of DKA, such as missed doses of insulin or underlying infection. ${ }^{5,6,9}$ In Case 2 the DKA episode was attributed to a Staphylococcus aureus line infection, with the level of acidosis thought to be exacerbated by a missed haemodialysis session. Had the patient's GCS not recovered despite resolution of DKA, further neurological investigations would have been warranted.

\section{Conclusion}

People who present with DKA and have ESKD can be critically ill

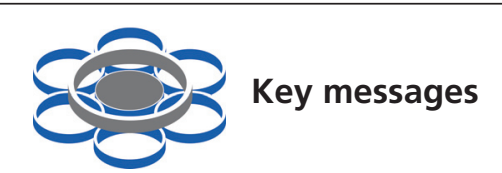

- A reduced rate of insulin infusion to mitigate the risk of hypoglycaemia. Insulin infusion rates should be adjusted in relation to haemodialysis timing.

- Careful monitoring of potassium, with replacement only if serum potassium is $<3.5 \mathrm{mmol} / \mathrm{L}$ and acidosis is corrected. Medical management of hyperkalaemia should be adapted in the context of hyperglycaemia if there is a delay to haemodialysis.

- Careful assessment of fluid volume status, with small boluses $(250 \mathrm{~mL})$ of intravenous fluids if deemed hypovolaemic and frequent re-assessment to avoid fluid overload. Invasive monitoring and vasopressor support in a critical care setting may be required in complex sepsis cases.

- As there are concerns regarding rapid reduction in hypertonicity in DKA, haemodialysis should be considered in cases with severe hyperkalaemia with ECG changes or severe pulmonary oedema.

and management needs to be tailored in response to each individual patient. It is important to understand that DKA can occur in both type 1 and type 2 diabetes, as the risks in type 2 diabetes may not be fully appreciated by non-specialists who may not see this very frequently. Suggestions and recommendations for management are based on very limited evidence in the form of case reports and observational studies only. There are no randomised controlled trials to guide patient care.

Key recommendations on the medical management of DKA in ESKD, based on this literature review, are highlighted in the box above.

It is important to involve specialists such as nephrologists, diabetologists and critical care early. Due to the complex care needs of the patients, there should be a low threshold to escalate to a critical care setting.

Conflict of interest $\mathrm{KH}$ is a member of the Joint British Diabetes Societies Inpatient Group. JOB reports personal fees from NAPP outside the submitted work. The other authors report no conflicts of interest.

\section{Funding None.}

Informed consent Written informed consent was obtained from the patient (Case 1) and next of kin (Case 2) for publication of this case report.

\section{References}

1. Iglesias P, Díez JJ. Insulin therapy in renal disease. Diabetes Obes Metab 2008;10(10):811-23. https://doi.org/10.1111/j.1463-1326.2007.00802.x

2. Joint British Diabetes Societies Inpatient Care Group. The management of diabetic ketoacidosis in adults. Second Edition. Update, 2013. http://www.diabetologists-abcd.org.uk/JBDS/JBDS_IP_DKA_Adults_Revised.pdf

3. Catalano C. Acute pulmonary oedema occurring in association with diabetic ketoacidosis in a diabetic patient with chronic renal failure. Nephrol Dial Transplant 1998;13(2):489-90. 
4. Blicker J, Herd AM, Talbot J. Diabetic ketoacidosis in the dialysis-dependent patient: two case reports and recommendations for treatment. CJEM 2004;6(4):281-4. https://doi.org/10.1017/s1481803500009271

5. Gupta A, Rohrscheib M,Tzamaloukas AH. Extreme hyperglycemia with ketoacidosis and hyperkalemia in a patient on chronic hemodialysis. Hemodial Int 2008;12(Suppl 2):S43-S47. https://doi.org/10.1111/ j.1542-4758.2008.00324.x

6. Varma R, Karim M. Lesson of the month 1: Diabetic ketoacidosis in established renal failure. Clin Med (Lond) 2016;16(4):392-3. https://doi.org/10.7861/clinmedicine.16-4-392

7. Yamada H, Funazaki S, Kakei M, Hara K, Ishikawa S. Diabetic ketoacidosis producing extreme hyperkalemia in a patient with type 1 diabetes on hemodialysis. Endocrinol Diabetes Metab Case Rep 2017;2017:17-0068. https://doi.org/10.1530/EDM-17-0068

8. Schaapveld-Davis CM, Negrete AL, Hudson JQ, et al. End-stage renal disease increases rates of adverse glucose events when treating diabetic ketoacidosis or hyperosmolar hyperglycemic state. Clin Diabetes 2017;35(4):202-8. https://doi.org/10.2337/cd16-0060

9. Seddik AA, Bashier A, Alhadari AK, et al. Challenges in management of diabetic ketoacidosis in hemodialysis patients, case presentation and review of literature. Diabetes Metab Syndr 2019;13(4):2481-7. https://doi.org/10.1016/j.dsx.2019.06.022

10. Popli S, Sun Y, Tang H, Kjellstrand C, Tzamaloukas A, Ing T. Acidosis and coma in adult diabetic maintenance dialysis patients with extreme hyperglycemia. Int Urol Nephrol 2013;45(6):1687-92. https://doi.org/ 10.1007/s11255-013-0390-6

11. Tzamaloukas AH, Avasthi PS. Serum potassium concentration in hyperglycemia of diabetes mellitus with long-term dialysis. West J Med 1987; 146(5):571-5.

12. Tzamaloukas AH, Avasthi PS. Acid-base disorders in hyperglycemia of insulin-dependent diabetic patients on chronic dialysis. J Diabetes Complications 1988;2(2):75-8. https://doi.org/10.1016/0891-6632(88)90007-4

13. Tzamaloukas AH, Rohrscheib M, Ing TS, et al. Serum potassium and acidbase parameters in severe dialysis-associated hyperglycemia treated with insulin therapy. Int J Artif Organs 2005;28(3):229-36. https://doi.org/10.1177/039139880502800307

14. Tzamaloukas AH, Ing TS, Siamopoulos KC, et al. Body fluid abnormalities in severe hyperglycemia in patients on chronic dialysis: review of published reports. J Diabetes Complications 2008;22(1):29-37. https://doi.org/10.1016/j.jdiacomp.2007.06.012

15. Tzamaloukas AH, Ing TS, Siamopoulos KC, et al. Pathophysiology and management of fluid and electrolyte disturbances in patients on chronic dialysis with severe hyperglycemia. Semin Dial 2008;21(5):431-9. https://doi.org/10.1111/j.1525-139X.2008.00464.x

16. Tzamaloukas $A$, Ing $T$, Elisaf $M$, et al. Abnormalities of serum potassium concentration in dialysis-associated hyperglycemia and their correction with insulin: review of published reports. Int Urol Nephrol 2011;43(2):451-9. https://doi.org/10.1007/s11255-010-9830-8

17. Kitabchi AE, Umpierrez GE, Murphy MB, Kreisberg RA. Hyperglycemic crises in adult patients with diabetes: a consensus statement from the American Diabetes Association. Diabetes Care 2006;29(12):2739-48. https://doi.org/10.2337/dc06-9916

18. Sobngwi $E$, Ashuntantang G, Ndounia $E$, et al. Continuous interstitial glucose monitoring in non-diabetic subjects with end-stage renal disease undergoing maintenance haemodialysis. Diabetes Res Clin Pract 2010;90(1):22-5. https://doi.org/10.1016/j. diabres.2010.06.001

19. Gai M, Merlo I, Dellepiane S, et al. Glycemic pattern in diabetic patients on hemodialysis: continuous glucose monitoring (CGM) analysis. Blood Purif 2014;38(1):68-73. https://doi.org/10.1159/000362863

20. Umpierrez G, Korytkowski M. Diabetic emergencies - ketoacidosis, hyperglycaemic hyperosmolar state and hypoglycaemia. Nat Rev Endocrinol 2016;12(4):222-32. https://doi.org/10.1038/nrendo.2016.15

21. Dhatariya KK, Umpierrez GE. Guidelines for management of diabetic ketoacidosis: time to revise? Lancet Diabetes Endocrinol 2017;5(5):321-3. https://doi.org/10.1016/S2213-8587(17)30093-1

22. Raimann JG, Kruse A, Thijssen S, et al. Metabolic effects of dialyzate glucose in chronic hemodialysis: results from a prospective, randomized crossover trial. Nephrol Dial Transplant 2012;27(4):1559-68. https://doi.org/10.1093/ndt/gfr520

23. Arieff Al. Dialysis disequilibrium syndrome: current concepts on pathogenesis and prevention. Kidney Int 1994;45(3):629-35. https://doi.org/ 10.1038/ki.1994.84

24. Zepeda-Orozco D, Quigley R. Dialysis disequilibrium syndrome. Pediatr Nephro/ 2012;27(12):2205-11. https://doi.org/10.1007/s00467-012-2199-4

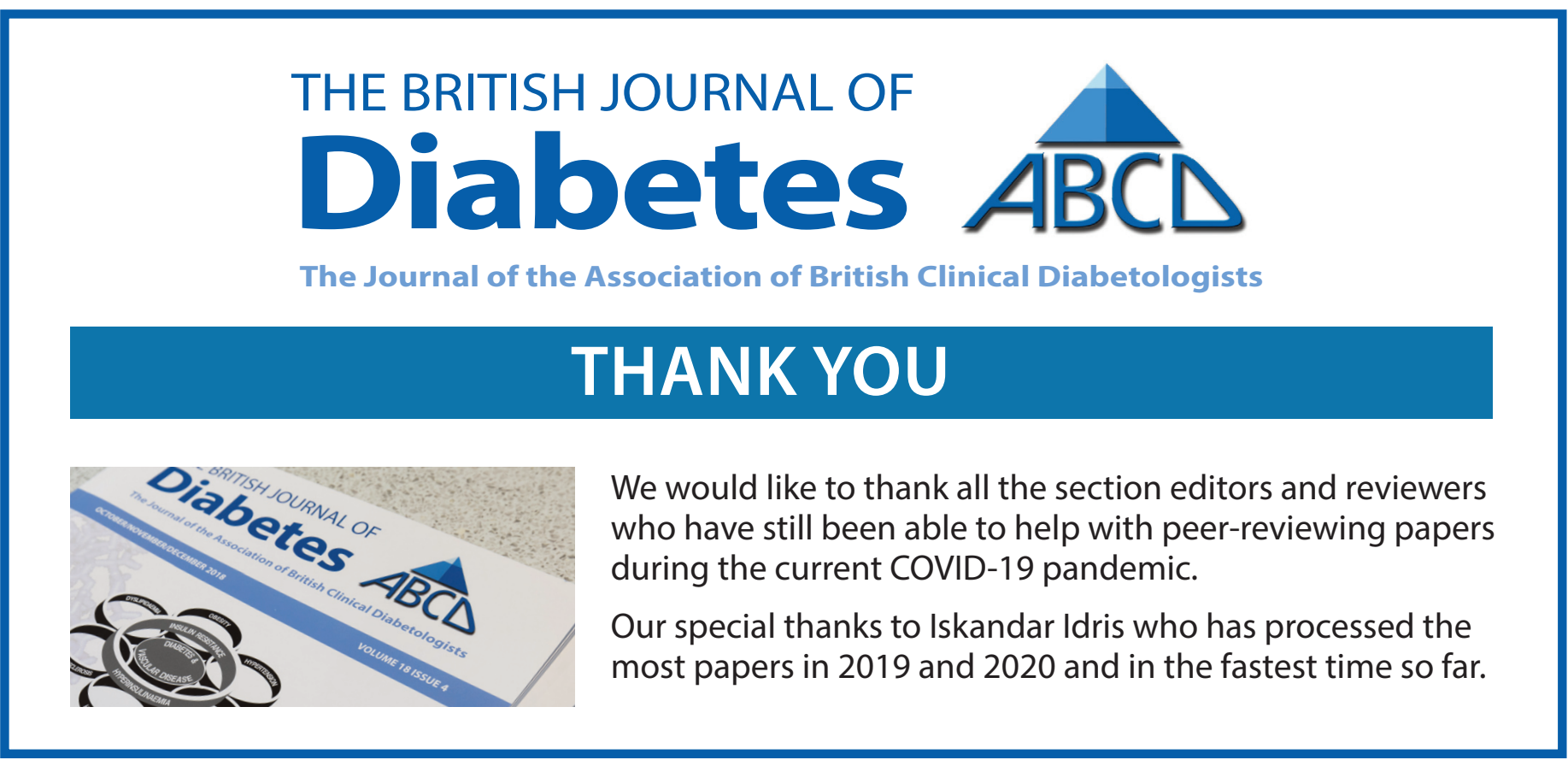

